\title{
Mudança da composição agrícola em duas regiões de Minas Gerais
}

\author{
Fernando Antônio Agra Santos ${ }^{1}$ \\ Roberto Araújo de Faria ${ }^{2}$ \\ Erly Cardoso Teixeira ${ }^{3}$
}

Resumo: O objetivo deste trabalho é analisar a evolução da área cultivada nas mesorregiões do Triângulo Mineiro/Alto Paranaíba e Zona da Mata, devido às grandes mudanças observadas na agropecuária mineira no período 1995/96 em relação a 1985. A metodologia divide-se em duas etapas: num primeiro momento será feita uma análise de decomposição da variação na área nos efeitos escala e substituição; a segunda etapa consiste em estimar um modelo econométrico da cultura que apresentou os maiores índices de expansão de área e de substituição sobre as demais, com o intuito de identificar os principais fatores responsáveis por tal desempenho. Observa-se que o arroz é a cultura que teve a sua área reduzida em todas as regiões, devido aos elevados custos de produção. Com relação ao café, verifica-se considerável expansão nas áreas colhidas na microrregião de Manhuaçu, principalmente por causa do clima e da topografia favoráveis. As pastagens destacam-se em termos de expansão de área nas duas mesorregiões. Ressalta-se que, à medida que a mão-de-obra torna-se escassa, mais se expandem as áreas com pastagens; para cada $1 \%$ de queda na oferta de mão-de-obra na região, a área com pastagens expande-se $0,8 \%$.

\footnotetext{
${ }^{1}$ Economista pela UFAL e Doutor em Economia Aplicada pela UFV.

E-mail: fernando.agra@yahoo.com.br

${ }^{2}$ Doutor em Economia Aplicada pela UFV.

${ }^{3}$ Professor do Departamento de Economia Rural da UFV. E-mail: teixeira@ufv.br
} 
Palavras-Chave: Composição agrícola, efeito escala, efeito substituição.

\begin{abstract}
This work analyzes the changes in area under cultivation that occurred between 1985 and 1995/1996 in the meso-regions Triângulo Mineiro/Alto Paranaíba and Zona da Mata in the state of Minas Gerais, Brazil. The analysis was conducted in two methodological stages. First, variation in the area under cultivation for a particular crop was disaggregated into variation due to change in regional agricultural scale and variation due to the substitution effect. Second, an econometric model of the crop that had the greatest growth in cultivated area and highest substitution effect index was developed to identify the main factors responsible for these high figures. It is observed that the area under rice cultivation was reduced in all regions, a fact related to the high cost of production. Coffee cultivation expanded in Manhuaçu, due mainly to the area's favorable climate and topography, and the area devoted to pasture expanded the most. It is stressed that the amount of land devoted to pasture increased as labor became more scarce: a $1 \%$ reduction in labor availability lead to a $0.8 \%$ increase in pasture.
\end{abstract}

Keys words: Agricultural composition, scale effect, substitution effect.

\title{
1. Introdução
}

Várias mudanças têm sido observadas na composição agrícola de Minas Gerais. Determinadas culturas têm migrado e se concentrado em regiões específicas, e algumas lavouras têm sido substituídas por outras. Indaga-se como se tem comportado, realmente, a composição agropecuária do estado de Minas Gerais no período 1995/96, em relação ao ano de 1985, e quais os principais fatores responsáveis por essas transformações ocorridas nas áreas cultivadas.

Este estudo tem como objetivo analisar a evolução da área cultivada do estado de Minas Gerais, nas microrregiões que compõem as mesorregiões do Triângulo Mineiro/Alto Paranaíba e Zona da Mata, comparando-se 1995/96 com 1985. Especificamente, torna-se importante, num primeiro momento, o desenvolvimento de análises georeferenciadas pela elaboração de mapas específicos, com o intuito de visualizar as 
principais mudanças estruturais e espaciais nas meso e microrregiões. A partir daí, selecionar-se-á a cultura que mais se destacou, tanto em crescimento em escala da área cultivada quanto em substituição das demais culturas nas regiões em análise.

Análises econômicas, como as realizadas por Gasquez e Villa Verde (1990) e Monteiro (1997), para explicar a evolução da produção agropecuária brasileira, ressaltam a importância de estudos regionais, e estes autores evidenciam a pouca capacidade de índices agregados (por estado, por exemplo) em expressar a realidade. Assim, quanto mais desagregadas as informações em microrregiões, maior a precisão das análises. Para estudar as mudanças na composição da produção agrícola, promovidas pela expansão da soja e pelo impacto provocado pelo processo de modernização em diversos estados, Igreja et al. (1988), Martins (1995) e Gomes (1990) adotaram uma versão modificada da análise Shift-Share.

\section{Metodologia}

Na perspectiva deste trabalho, o conceito de competitividade está relacionado com as alterações da área plantada (Martins, 1995) entre as principais culturas nas mesorregiões selecionadas para a realização desta pesquisa, são elas: Triângulo Mineiro/Alto Paranaíba e Zona da Mata, dadas suas relevantes participações no PIB agrícola do estado de Minas Gerais. Entre as principais culturas selecionadas, citam-se abacaxi, abóbora, algodão em caroço, amendoim, arroz, batata-doce, batata-inglesa, cana-de-açúcar, cebola, feijão, mandioca, milho, soja, tomate, trigo, forrageiras, banana, café, laranja e pastagens plantadas.

A metodologia divide-se em duas etapas. Num primeiro momento, por meio do Modelo Shift-Share, serão calculados os efeito-escala e efeitosubstituição das culturas supracitadas, tanto para as meso quanto para as microrregiões em estudo. Será bem como será elaborado um índice que corresponderá à razão entre o efeito-substituição e a variação total da área da região em análise, para cada cultura, com o intuito principal de explicitar as culturas que mais substituíram (sinal positivo) outras culturas e as que mais foram substituídas (sinal negativo) por elas. Inicialmente, 
analisam-se as alterações na composição agrícola da área em estudo. Para tal, será adotado o modelo Shift-Share, aplicado por autores como Zockun (1978), Yokoyama et al. (1989), Gomes et al. (1998), Pimentel (1998) e Shikida et al. (1999), que procederam a análises semelhantes às almejadas no presente estudo. Este modelo permite decompor a alteração da área cultivada de um produto em relação a outro, em função da variação do tamanho do sistema (que corresponde ao somatório da área cultivada com os produtos plantados na região em análise) de produção (efeitoescala), ou da substituição de um produto por outro, dentro do sistema (efeito-substituição).

O primeiro modelo analítico será representado pela seguinte expressão:

$$
A_{i 2}-A_{i 1}=\left(\alpha A_{i 1}-A_{i 1}\right)+\left(A_{i 2}-\alpha A_{i 1}\right)
$$

em que $A_{i 2}-A_{i 1}=$ variação da área cultivada com uma atividade específica "i”, entre o período 2 e $1 ;\left(\alpha A_{i 1}-A_{i 1}\right)=$ efeito-escala; $\left(A_{i 2}-\alpha A_{i 1}\right)=$ efeito-substituição, sendo:

$$
\alpha=A_{t 2} / A_{t 1} ; A_{t 1}=\sum_{i} A_{i 1} ; A_{t 2}=\sum_{i} A_{i 2}
$$

em que $\mathrm{A}_{\mathrm{i}}$ corresponde à área cultivada com a i-ésima atividade; $\mathrm{i}=1$, $2, \ldots, n$ atividades analisadas; $\mathrm{A}_{\mathrm{t} 1}$ é o tamanho do sistema no período 1; $A_{t 2}$ é o tamanho do sistema no período 2; e $\alpha$ é a relação entre $A_{t 2}$ e $A_{t 1}$, que mede a alteração do tamanho do sistema de produção.

O efeito-escala é dado pela variação na área do produto apenas pela alteração do tamanho do sistema, mantendo inalterada sua participação dentro deste. Se os valores forem positivos, representam uma tendência de expansão das culturas; se forem negativos, representam uma tendência de diminuição na produção das culturas dentro do sistema. Os valores encontrados no efeito-escala para cada produto mostram como seria o comportamento de cada cultura, se a ampliação ou a contração da área total fosse distribuída de modo uniforme entre elas.

O efeito-substituição mostra a variação da participação dentro do sis- 
tema, ou seja, refere-se à diferença entre a variação real da área cultivada, entre os períodos em análise, e o efeito-escala. Isso quer dizer que, quando o efeito-substituição for negativo, por exemplo, não significa, necessariamente, que sua área cultivada tenha sido reduzida; ela pode, simplesmente, ter se expandido, porém, numa magnitude menos que proporcional ao crescimento total da área na região em análise. Isso implica dizer que essa cultura teve suas áreas, de modo geral, substituídas por outra cultura, que se expandiu mais que proporcionalmente ao crescimento da área total dentro do sistema. Caso o efeito-substituição apresente sinal positivo, a situação é simétrica à supracitada. Em suma, as culturas que apresentarem efeito-substituição positivo substituíram outras culturas e as atividades que apresentarem efeito-substituição negativo foram substituídas por outras.

Os resultados obtidos para cada cultura são apresentados nas Tabelas 1 e 2 e na Figura 1 (mapas temáticos), gerados pelo software IDRISI 2.0, de informação geográfica. Utilizado para tal finalidade, o mapa vetorial do estado de Minas Gerais foi importado do site Geominas (http//:www.geominas.mg.gov.br).

A segunda etapa da metodologia refere-se à seleção da cultura que mais se destacou tanto em expansão de área quanto em substituição às demais culturas das regiões em estudo, com a finalidade de identificar os principais fatores responsáveis pelos resultados observados:

$$
\text { Ln EE }=\alpha_{0}+\alpha_{1} F+\alpha_{2} I+\alpha_{3} M+\alpha_{4} D+\mu \text {, }
$$

em que Ln EE = logaritmo natural do efeito-escala da cultura que mais se destacou, expresso em hectares; $\mathrm{F}$ = variação dos valores dos financiamentos para o custeio entre 1985 e 1995/96, segundo as microrregiões, expressos em reais, a preços de dezembro de 1995; I = variação dos valores dos investimentos totais (terras adquiridas, prédios, instalações e outras benfeitorias, veículos e outros meios de transporte, máquinas e implementos e compra de animais), entre 1985 e 1995/96, segundo as microrregiões, expressos em reais, a preços de dezembro de 1995; M = variação no número de empregados temporários entre 1985 e 1995/96, segundo as microrregiões; D = Variável Dummy: 0 = Triângulo Mineiro/Alto Paranaíba, 1 = Zona da Mata; $\mu$ = Erro aleatório.

Vale observar que, tanto o efeito-escala quanto o efeito-substituição são 
calculados a partir de dados referentes às variações das áreas cultivadas. Com isso, a fim de manter a representatividade do modelo apresentado, todos os valores das variáveis selecionadas (F, I, e M) correspondem a variações entre 1985 e 1995/96. Com vistas em abranger os fatores de produção clássicos, foram selecionados: valores dos investimentos totais, como proxy para os fatores capital e terra; e os empregados temporários são relativos ao fator mão-de-obra. Por fim, vale dizer que se optou pela estimação (pelo Método dos Mínimos Quadrados Ordinários) de um modelo logaritmo-linear, por considerá-lo representativo da realidade examinada. Os dados para realização das etapas referidas foram extraídos do Censo Agropecuário do estado de Minas Gerais, referentes aos anos de 1985 e 1995/96, provenientes da FIBGE.

\section{Resultados e discussões}

Inicialmente, serão feitas considerações baseadas tanto nas Tabelas 1 e 2, que apresentam os efeito-escala e efeito-substituição, para as mesorregiões em análise, quanto nos mapas temáticos das microrregiões (Figura 1), de modo a propiciar melhor visualização das modificações na composição agrícola das áreas em estudo, mostrando quais as culturas mais substituídas e quais as que mais tiveram suas áreas ampliadas, para, posteriormente, inferir sobre os principais fatores responsáveis pelas tendências observadas.

A priori, torna-se relevante apresentar algumas considerações: os dados dispostos nas Tabelas 1 e 2 apresentam, em nível agregado de mesorregião, as áreas colhidas (ha) das culturas em estudo, nos períodos 1985 e 1995/96; a variação destas entre tais períodos; o efeitos-escala e o efeito-substituição; e, por fim, a última coluna de cada Tabela apresenta uma razão entre o efeito-substituição e a variação total da área colhida (esse índice permitirá, realmente, verificar a magnitude daquelas culturas que substituíram outras, no período em análise). Em geral, vale reafirmar que as culturas que apresentarem efeito-substituição positivo substituíram e as que apresentarem efeito-substituição negativo foram substituídas por outras culturas. Em seguida, a Figura 1 apresenta os mapas do estado de Minas Gerais com a razão efeitos-substituição/variação da área, das principais culturas para as mesorregiões em estudo.

Inicialmente, serão analisados os efeitos sobre a mesorregião do Tri- 
ângulo Mineiro/Alto Paranaíba, no qual houve expansão de 16,77\% na área total cultivada das culturas em estudo. Verifica-se, entretanto, que algumas culturas ampliaram enquanto outras reduziram suas áreas. Entre as principais culturas que elevaram suas áreas colhidas, podem-se destacar a cana-de-açúcar, as forrageiras, café, milho e, principalmente, as pastagens plantadas; enquanto o feijão e, sobretudo, o arroz tiveram suas áreas colhidas diminuídas.

Conforme a Tabela 1, a cultura do arroz foi a que mais reduziu sua área cultivada. De modo geral, a área total colhida na mesorregião do Triângulo Mineiro/Alto Paranaíba se expandiu 16,77\%. Se tal crescimento fosse uniformemente distribuído entre todas as culturas, o arroz deveria se expandir nessa mesma proporção. Entretanto, o que se verificou foi brusca redução de 153.985 ha em 1985 para 24.000 ha em 1995/96, evidenciando uma queda de $84,5 \%$ na área colhida com esse produto. Com isso, é possível dizer que a cultura do arroz teve sua área substituída pelas demais culturas nessa magnitude.

Observando-se a Figura 1, relativa à cultura do arroz, verifica-se que, em todas as microrregiões, tal produto teve suas áreas substituídas por outras culturas. Entre outros fatores econômicos que tentam explicar o que foi descrito, está a concorrência com o arroz produzido nos estados do Sul do Brasil, que apresenta melhor qualidade, sobretudo no tipo longo, além de menor custo de comercialização. Outro fator que tem desestimulado a produção de arroz nas mesorregiões está relacionado com o alto custo de produção desse produto cultivado em brejo, que ainda é muito dependente da mão-de-obra. Em 1994/95, os custos de produção de um hectare de arroz, em Minas Gerais, eram de US\$ 925,05, em que US\$159,38 eram relativos à participação da mão-de-obra fixa, e, em 1995/96, o custo total foi reduzido para US\$ 902,93/ha, enquanto a participação com mão-de-obra fixa aumentou para US\$177,23. Além disso, observa-se que produtores têm enfrentado sérias dificuldades com o processo de abertura comercial, visto que, em países como o Uruguai, os custos têm média de US\$ 819,49/ha. Países asiáticos, como a Tailândia, têm conseguido ampliar a oferta de arroz no mercado brasileiro, pressionando ainda mais os preços, que, em 1990, estavam em torno de US\$17,73, chegando a US\$12,22 a saca, em 1995 (FNP, 1999). 


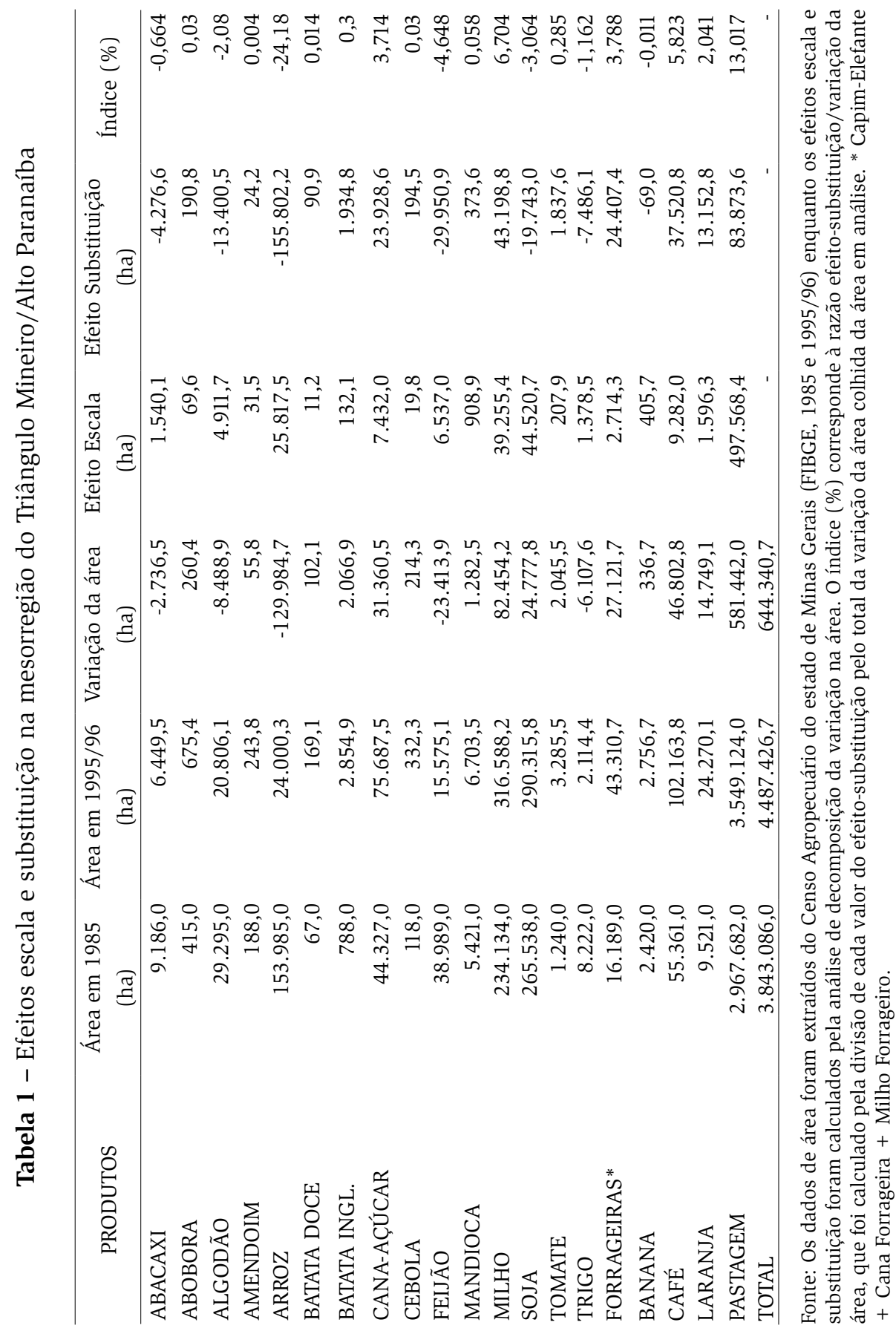




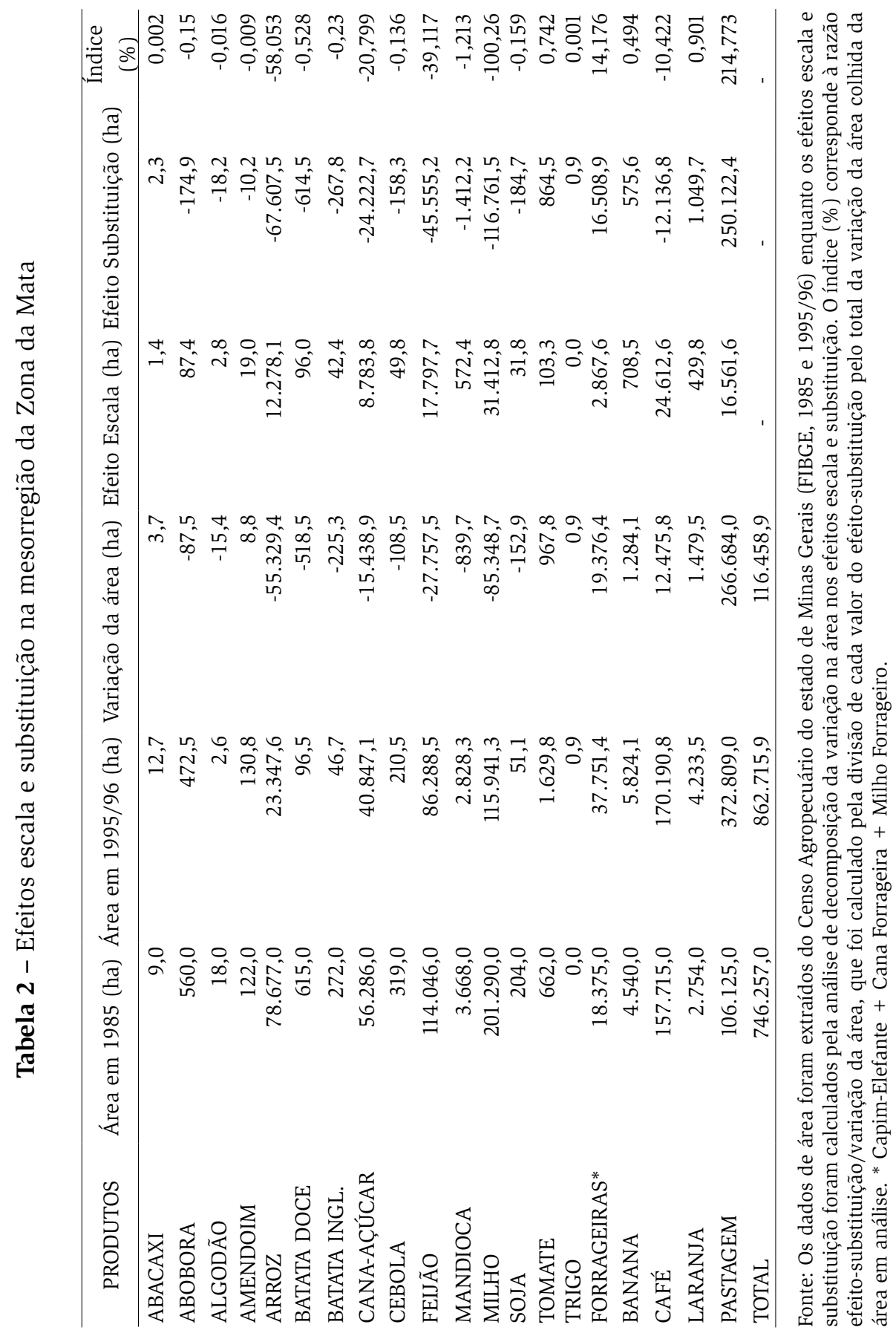




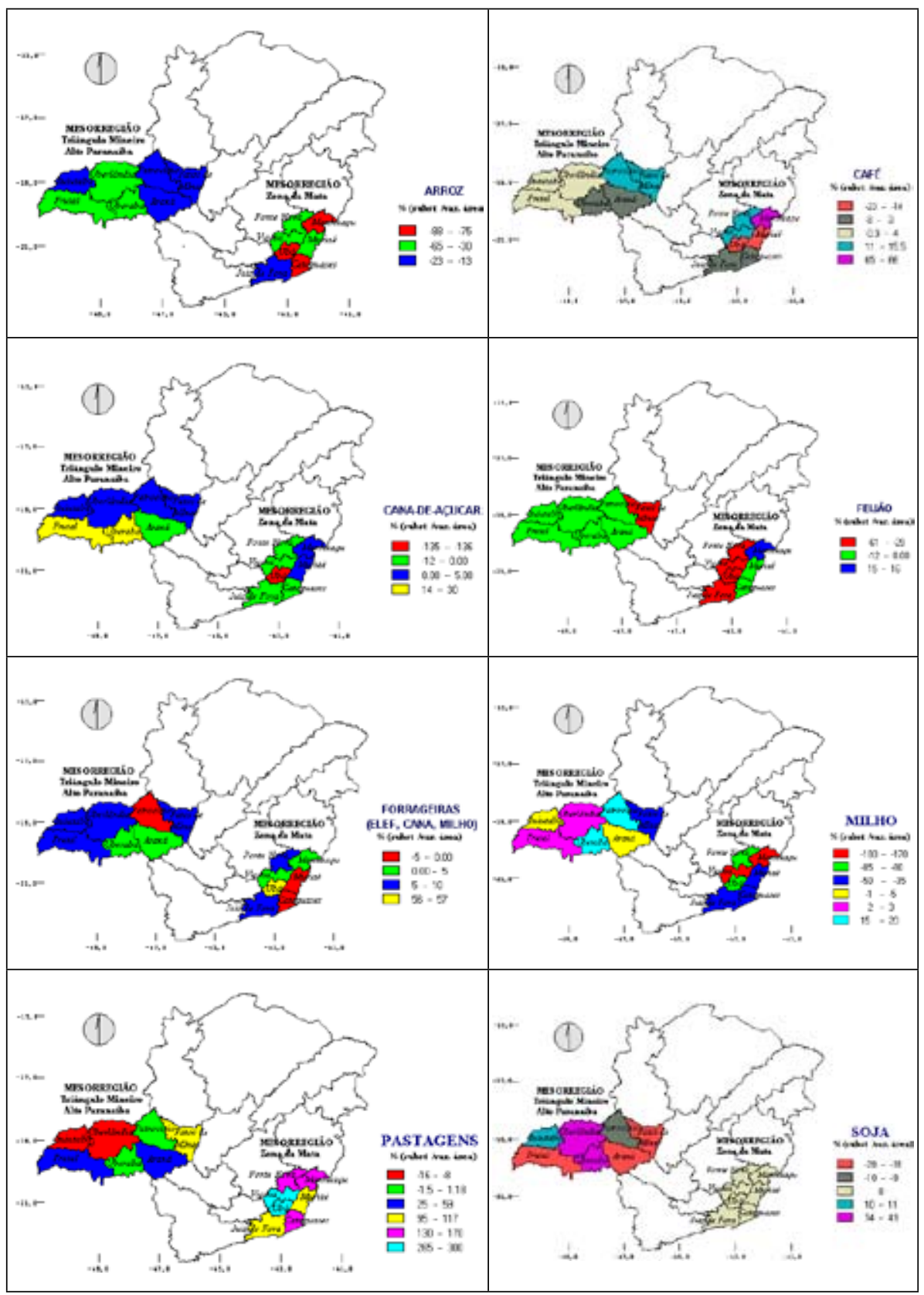

Figura 1 - Mapas de Minas Gerais com a razão efeitos substituição/variação da área. 
A área cultivada com milho vem recuando na Zona da Mata, em conseqüência dos fatores edafoclimáticos e topográficos. Diferentemente desta mesorregião, a área com o cultivo de milho tem crescido bastante no Triângulo Mineiro/Alto Paranaíba, onde predomina uma agricultura empresarial, altamente tecnificada, além de condições climáticas e geográficas favoráveis nessa região. De modo geral, os custos para se produzir uma saca de milho no Triângulo Mineiro está em torno de US\$ 4,35 (segundo menor custo de produção do Brasil, ficando atrás apenas do Paraná, que tem um custo de US\$ 4,30), enquanto na Zona da Mata os custos sobem para US\$ 6,50. Conseqüentemente, a área com o milho tem apresentado forte queda na Zona da Mata. Em 1995/96, foram colhidos 115.941 ha de milho (Tabela 2), em 1996/97, 105.000 ha, em 1997/98, apenas 95.000 ha e, em 1998/99, 87.000 ha (Emater 1999). Com isso, a produção de milho na Zona da Mata não tem sido suficiente para atender à demanda do pólo suinícola em Ponte Nova (MG) e o avícola em Visconde do Rio Branco (MG), os quais são abastecidos com o milho procedente do Triângulo Mineiro e até do estado de Goiás.

Em relação à cultura do café na Zona da Mata, houve um crescimento de 12.475 ha na área, porém, em menor proporção que o crescimento em escala do sistema. Isso significa que, de modo geral, a cultura de café foi substituída pelas demais, conforme mostra o efeito-substituição de -12.136 ha (Tabela 2). Ressalta-se que, nessa mesorregião, tanto a área quanto a própria produção vêm declinando, principalmente desde o início dos anos 90. A explicação dessa situação vem, em parte, do rompimento do AIC (Acordo Internacional do Café), em 1989, que fez com que o sistema de cotas de produção nos principais países fosse rompido. Conseqüentemente, a oferta mundial teve forte aumento, pressionado os valores do produto, que, junto com a extinção do IBC (Instituto Brasileiro do Café) em 1990, no governo Collor, forçou uma crise na safra 1992/93, desestimulando a produção do café. A partir de 1994, a recuperação do preço do café no mercado internacional, por conta do aumento na demanda, tem estimulado a produção, conseqüentemente, a área com café tem se ampliado. Essa recuperação na produção é observada no Triângulo Mineiro/Alto Paranaíba, uma vez, que nessas regiões, a topografia possibilita adoção de tecnologias 
que proporcionam a redução de custos, em especial, a mecanização da colheita. Na Zona da Mata, a região de Manhuaçu, sofreu menos os impactos de uma conjuntura desfavorável, conforme mencionado, em razão da tradição no cultivo do café e da existência de maior estrutura de beneficiamento e comercialização, de modo a favorecer a recuperação da área e da produção após os anos de crise.

Quanto à cana-de-açúcar, destacam-se as microrregiões de Frutal e Uberaba, onde as áreas com essas culturas foram ampliadas mais intensivamente, em razão, sobretudo, das condições edafoclimáticas favoráveis, bem como da proximidade ao maior e mais desenvolvido centro produtor sucroalcooleiro, que é o estado de São Paulo, visto que o acesso às técnicas mais modernas facilita a expansão da produção nessas microrregiões. Já na Zona da Mata, a situação tem sido diferente, visto que, na maioria das suas microrregiões, a área colhida com a cana-deaçúcar tem diminuído, sendo uma das culturas que mais tem cedido áreas para outras culturas, fato corroborado pelo elevado índice efeitosubstituição/variação da área, -20,799\% (Tabela 2). O motivo para essa forte redução na área seria a desativação do Proálcool. Boa parcela das usinas diminuiu sua produção de álcool e ampliou a produção de açúcar, aumentando a oferta e reduzindo os preços, que passaram de US\$ 11,81/t, em 1989, para US\$10,73/t, em 1993 (Emater, 1999).

Para o feijão, pode-se verificar, pelos resultados das Tabela 1 e 2, um declínio na área colhida nas duas mesorregiões consideradas. A redução da área de consórcio, devido à redução do espaçamento em café e da redução da área plantada com milho, tem sido um dos principais fatores responsáveis pela situação observada, mais especificamente na Zona da Mata. Entretanto, nos últimos anos, a produção de feijão com o plantio da chamada $3^{\text {a }}$ safra vem crescendo de forma significativa, sobretudo na microrregião de Manhuaçu. Vale ressaltar que a cultura do feijão, por conta de seu período curto de safra (máximo de 90 dias), da oscilação na produção e da área colhida, responde muito rápido às variações do preço do produto, à intervenção governamental e aos fatores climáticos (Gomes et al., 1991).

Quanto à cultura da soja, esta tem apresentado um crescimento nas áreas colhidas em Ituiutaba, Uberaba e Uberlândia, e verifica que praticamente não se produz essa cultura na Zona da Mata. Ao estudarem 
a mudança na composição agrícola do estado de Goiás, no período de 1969 a 1985, Igreja et al. (1988) destacaram a importância do avanço da soja. Observou-se, neste trabalho, que o predomínio do avanço da soja em área de outras culturas continua expressivo nas microrregiões mais próximas a Goiás. Entretanto, ressalta-se que os preços da soja, em 1994/95, foram desestimulantes, chegando a US\$ 8,50/saca, em meados de 1995. A situação dos sojicultores agravou-se, a ponto de muitos chegaram à beira da falência, o que resultou nas negociações para a securitização de suas dívidas. Já na safra 1995/96, os preços se recuperaram, chegando a US\$13,51/saca.

Observando-se as forrageiras (capim elefante, cana e milho forrageiros) e as pastagens, verifica-se tendência de expansão das áreas com as referidas culturas, na maioria das microrregiões, principalmente das pastagens, quando se observam os elevados valores encontrados na razão do efeito-substituição sobre a variação total das áreas colhidas, sobretudo nas microrregiões que compõem a Zona da Mata. Isso confirma um crescimento no efetivo bovino do estado, o que levou Minas Gerais a deter o maior número de cabeças de gado, cerca de 21.296.131 no período, superando o estado do Mato Grosso do Sul, que possuía 21.129.651. Vale ressaltar que, de 1985 a 1995/96, o preço do boi gordo passou de US\$14,10/@ para US\$26,2/@, estimulando a ampliação das áreas com pastagens (FNP, 1999).

Tendo em vista que a pastagem foi o que mais substituiu outras culturas em ambas as mesorregiões (apresentando índices de efeitosubstituição/variação da área de $13,02 \%$ e de $214,77 \%$, no Triângulo Mineiro/Alto Paranaíba e Zona da Mata, respectivamente, explicitados na quinta coluna das Tabelas 1 e 2), selecionou-se tal cultura para identificar os principais fatores responsáveis pelos resultados observados. $\mathrm{O}$ modelo estimado foi o seguinte:

$$
\begin{aligned}
& \text { Ln EEP }=11,0027^{* * *}+0,000010 \mathrm{~F}^{\mathrm{NS}}+0,000013 \mathrm{I}^{* *}-0,000210 \mathrm{M}^{* * *}-2,9096 \mathrm{D}^{* * *} \\
& \begin{array}{ccccc}
(24,17) & (0,40) & (3,15) & (-5,10) & (-5,80) \\
\mathrm{n}=14 & \mathrm{R}^{2}=0,96 & & \text { Teste } \mathrm{F}=24,3275^{* * *}
\end{array}
\end{aligned}
$$

*** significativo a $1 \%$ de nível de significância; ** $5 \%$ de nível de significância; NS: Não-significativo. 
Com relação à significância dos parâmetros estimados, pode-se perceber que os coeficientes relacionados com o fator mão-de-obra (M) e valor dos investimentos totais (I) apresentaram-se estatisticamente significativos a $1 \%$ e $5 \%$, respectivamente, enquanto o coeficiente relacionado com o valor dos financiamentos para custeio (F) não se apresentou estatisticamente significativo. Com relação aos sinais dos coeficientes estimados acima, pode-se verificar que o valor dos investimentos se relaciona, positivamente, com o crescimento das áreas com pastagens, enquanto pode-se observar relação negativa com o fator mão-de-obra. A limitação de crédito para custeios das pastagens é um dos fatores que explicam a não-significância estatística da variável relativa a financiamentos, no modelo estimado. A variável Dummy, significativa a $1 \%$ de probabilidade, revela que a equação para pastagens é estatisticamente diferente para as regiões em análise, o que é corroborado por fatores edafoclimáticos e geográficos.

O modelo registrou elevado coeficiente de determinação $\left(\mathrm{R}^{2}=\right.$ 0,96), indicando que o modelo explica $96 \%$ das variações da variável dependente. $O$ teste " $F$ " apresentou-se significativo a $1 \%$ de probabilidade, ou seja, pode-se afirmar que o modelo logaritmo-linear do efeito-escala das pastagens tem suporte estatístico. Com relação às Elasticidades Parciais de Área $\left(\xi_{\mathrm{EE}, \mathrm{I}},=0,35\right.$ e $\left.\xi_{\mathrm{EE}, \mathrm{M}}=-0,79\right)$, pode-se verificar relação inelástica de todos os fatores em estudo, quanto à expansão da área com pastagens. Verifica-se que um aumento de $1 \%$ na variação dos recursos canalizados para os investimentos provoca uma expansão de $0,35 \%$ no efeito-escala com as pastagens, uma vez que a natureza dos investimentos na pecuária é de médio e longo prazos.

Entre outros fatores responsáveis pela ampliação das pastagens nas duas mesorregiões em análise, a rentabilidade dessa cultura não está incluída, mas em substituição a outras atividades consideradas mais arriscadas e que exigem maior volume de mão-de-obra. No caso das pastagens, como revela o modelo, há relação inversa entre expansão da área (verificado pelo efeito escala) e necessidade de mãode-obra. 


\section{Conclusões}

Tanto no Triângulo Mineiro/Alto Paranaíba quanto na Zona da Mata a área total com as culturas analisadas cresceram 16,77\% e $15,61 \%$, respectivamente, porém, de modo não uniforme. Entre os principais resultados, destacam-se as culturas de arroz, milho, café e pastagens.

A cultura do arroz foi a que teve a área mais reduzida em todas as regiões em análise, com a causa principal relacionada aos elevados custos de produção do produto, cultivado em Várzea Úmida, altamente dependente de mão-de-obra. Além disso, o arroz tem forte concorrência com as importações do Uruguai e de países asiáticos (acentuadas desde o início do processo de abertura comercial).

Com relação ao café, destacam-se duas fases importantes no período analisado. Uma foi a crise causada tanto pelo rompimento do AIC, em 1989 (que refletiu em queda dos preços), quanto pela extinção do IBC, que desestimulou a produção. A partir de 1994, a situação começa a se inverter, observando-se considerável expansão nas áreas colhidas com café na microrregião de Manhuaçu (Zona da Mata). Essa recuperação na produção é também observada no Triângulo Mineiro, uma vez que, a topografia nessa mesorregião possibilita adoção de tecnologias que proporcionam a redução de custos, em especial a mecanização da colheita.

Quanto ao milho, fatores topográficos e edafoclimáticos, entre outros, têm feito com que os custos de produção na Zona da Mata aumentem. Com isso, a cultura de milho tem declinado sensivelmente sua área, razão pela qual sua produção tem caído ano a ano. Entretanto, a situação no Triângulo Mineiro/Alto Paranaíba é bem distinta, já que as áreas com o milho têm aumentado em razão de fatores de ordem climática e empresarial, o que tem reduzido seus custos de produção.

As pastagens destacam-se em relação à expansão de área e substituição pelas demais culturas. Um dos principais responsáveis por esse desempenho é a busca, por parte dos agricultores, de outras atividades menos arriscadas e que demandem menor contingente de mão-de-obra. 
Agradecimentos: Os autores agradecem a Niwton Castro Moraes (Emater/MG), Flávio Lúcio Rigueira (Emater/MG) e ao Professor João Eustáquio de Lima (DER/UFV).

\section{Referências bibliográficas}

EMATER. Comunicação pessoal. Viçosa (MG), 1999.

FIBGE (FUNDAÇÃO INSTITUTO DE GEOGRAFIA E ESTATÍSTICA). Censo Agropecuário do Estado de Minas Gerais, Série Regional de Minas Gerais. Rio de Janeiro: 1985 e 1995/96.

FIBGE (FUNDAÇÃO INSTITUTO DE GEOGRAFIA E ESTATÍSTICA). Anuário Estatístico do Brasil, 1995; http:www.sidra.ibge.gov.br.

FNP (Consultoria \& Comércio). Agrianual \& Anualpec, 1999.

GASQUEZ, J.G. \& VILLA VERDE, C.M. Crescimento da agricultura brasileira e política agrícola nos anos oitenta. São Paulo: IPEA, 1990.

GOMES, M.F.M., Efeitos da expansão da produção de soja em duas regiões do Brasil. Viçosa, DER/UFV, 1990. 105p (Dissertação de Doutorado).

GOMES, M.F.M., LIMA, J.E., GOMES, S.T. \& TEIXEIRA FILHO, A.R. Efeitos da expansão da produção de soja em duas regiões do Brasil. Revista de Economia e Sociologia Rural. Brasília: 29(3), jul./set. 1998, pp. 209-227.

IGREJA, A.C.M., PACKER, M.F. \& ROCHA, M.B. A evolução da soja no Estado de Goiás e seu impacto na composição agrícola. Instituto de Economia Agrícola, São Paulo, 1988, 20p.

MARTINS, R.S., O comportamento da competitividade da soja no Estado do Paraná - 1970/95, Informe Econômico: EMBRAPA/CNPSo, Londrina: 2(2):21-24, agosto/1995.

MONTEIRO, M.J.C. Produtividade física das lavouras: um sucesso ignorado. Revista Agroanalysis. Rio de Janeiro: maio/1997. p.17-19.

PIMENTEL, C.R. Evolução recente e tendências da fruticultura nordestina. Revista Econômica do Nordeste. Fortaleza: v. 29, n 1, jan./ mar. 1998, pp. 11-19. 
SHIKIDA, P.F.A., ALVES, L.R.A. \& SANTOS, C.V. Aspectos da agroindústria canavieira do Paraná: Panorama estrutural e dinâmica de crescimento. Anais do XXXVII Congresso Brasileiro de Economia e Sociologia Rural (CD-Room). Foz do Iguaçu: 1999.

YOKOYAMA, L.P., IGREJA, A.C.M. \& NEVES, E.M. Modelo "Shift-Share”: Uma readaptação metodológica e uma aplicação para o Estado de Goiás. Anais do XXVII Congresso Brasileiro de Economia e Sociologia Rural. Piracicaba: 1989, pp. 63-78.

ZOCKUN, M. H. G. P. A expansão da soja no Brasil: alguns aspectos da produção. São Paulo: USP/FEA, 1978. 228p (Dissertação de Mestrado). 